\title{
Diagnostic and Prognostic Role of Liver Elastography in Heart Failure
}

Diane Xavier Ávila, ${ }^{\circledR}$ Priscila Abreu Matos, ${ }^{\circledR}$ Gabriel Quintino, ${ }^{\circledR}$ Wolney de Andrade Martins, ${ }^{\circledR}$ Dalmo Machado, Claudio Tinoco Mesquita, Humberto Villacorta Junior ${ }^{\circledR}$

Universidade Federal Fluminense, Niterói, RJ - Brazil

\section{Abstract}

Background: Hepatic congestion is a frequent finding in patients with heart failure (HF). Physical examination has limitations in quantifying systemic congestion and requires correlation with echocardiographic and laboratory data (usually B-type natriuretic peptide, BNP, or N-terminal pro-B type natriuretic peptide, NT-proBNP). Hepatic elastography evaluates liver stiffness using a transducer that transmits low-frequency vibrations $(50 \mathrm{~Hz})$, and the speed of shear waves propagating through the tissues is measured by ultrasound. The faster the vibrations propagate in the hepatic parenchyma, the stiffer the liver, which, in case of HF, can be correlated with hepatic congestion.

Objective: In this systematic review, case-controls, cohort studies, and randomized clinical trials were searched in MEDLINE, LILACS and Cochrane Database of Systematic Review, to evaluate the use of elastography in the detection of hepatic congestion in patients with HF.

Methods: From the 49 articles retrieved, seven were selected for review, according to the inclusion and exclusion criteria. The most used methods for the diagnosis and evaluation of HF were echocardiography combined with BNP and NT-proBNP measurements.

Results: Elastography performed at bedside was able to establish a significant correlation between increased liver stiffness and increased venous capillary pressure. In addition, liver elastography performed at hospital discharge was able to predict rehospitalization and mortality.

Conclusion: Liver elastography is a non-invasive method that can be useful in predicting prognosis and mortality of individuals with HF, contributing to the clinical management of these patients. (Int J Cardiovasc Sci. 2020; 33(3):227-232)

Keywords: Heart Failure/physiopathology; Heart Failure/mortality; Hepatic Congestion; Elastography; Ultrassonography/methods; Echocardiography/methods; Hospitalizartion; Humans.

\section{Introduction}

Heart failure (HF) is a highly prevalent syndrome, affecting $1 \%$ to $2 \%$ of the world population and more than $10 \%$ of people over 70 years of age. ${ }^{1-3}$ In Brazil, $9.3 \%$ of people older than 45 years have $\mathrm{HF}^{4}$ and according to the BREATHE registry (Brazilian Registry of Acute Heart Failure), hospital mortality for decompensated $\mathrm{HF}$ is $12.6 \% .^{5} \mathrm{HF}$ is a clinical condition characterized by signs and symptoms related to systemic hypoperfusion and capillary congestion, that affect class functional status and quality of life of individuals. With increased filling pressures and damping of blood flow, the liver is affected by congestion secondary to HF. ${ }^{6-9}$ The impact of $\mathrm{HF}$ on liver function was described a long time ago, and the pathophysiological relationship is confirmed by small changes in hepatic markers even in the absence of a diagnosis of liver disease. ${ }^{6}$ In this regard, based on the various etiologies and comorbidities in HF, it becomes relevant to know the methods for assessing hepatic congestion and the mechanisms of associated injuries.

Liver elastography is an imaging test that evaluates liver stiffness using an ultrasound transducer operating at $5 \mathrm{MHz}$. The device transmits low-frequency vibrations

Mailing Address: Diane Xavier Ávila

Universidade Federal Fluminense - Cardiologia - Rua Marquês do Paraná, 303, 6ª andar. Postal Code: 24030-215, Centro, Niterói - Brazil

E-mail: dianeavilamed@gmail.com, dianeavilamed@yahoo.com.br 
$(50 \mathrm{~Hz})$ and the speed of shear waves propagating through the tissues is measured by ultrasound. The stiffer the hepatic parenchyma, the faster the vibrations are propagated. The waves are measured in kiloPascals $(\mathrm{kPa})$, and this measure may correlate with hepatic congestion. The transducer is placed in the intercostal space at the intersection of the mid-axillary line and a transverse line at the level of the xiphoid process. The result of the elastography represents the average of all valid acquisitions and varies from 2.5 to $75 \mathrm{kPa}$. Elastography is reliable when all these criteria are met: 10 valid measurements, an interquartile range (IQR) $<30 \%$ of the average and a success rate $>60 \%$. Two transducers are available: the standard " $\mathrm{M}$ " probe, used in non-obese patients, and the "XL", used for obese patients or when the results produced by the $\mathrm{M}$ probe are unreliable. The reference value of elastography in healthy subjects is around $5.5 \mathrm{kPa}$ with the $\mathrm{M}$ transducer.

With the aging of the population, an increase in the incidence of $\mathrm{HF}$ is expected. Advances in medicine and in the treatment of cardiovascular diseases will increase life expectancy, and consequently, the number of elderly individuals will also increase. ${ }^{6}$ Thus, with the increasing trend of the prevalence of $\mathrm{HF}$, there is a growing need for methods that facilitate the management of these patients, mainly because subclinical congestion is a common cause of early rehospitalization in HF.

The objective of this study was to evaluate the use of elastography in the detection of hepatic congestion in patients with HF in different clinical settings, and its prognostic role in these patients.

\section{Methods}

A systematic review was performed following the Preferred Reporting Items for Systematic Reviews and Meta-Analyses (PRISMA) guidelines. ${ }^{10}$ The inclusion criteria of the studies were: articles written in English or Portuguese that included hepatic elastography in the assessment of congestion in patients with HF. Data were extracted in a standardized manner by two independent investigators, who were also responsible for evaluating the methodological quality of the manuscripts. Articles in duplicate, review studies, editorials, letters to the editor and experimental studies in animals were excluded. The search in the literature was conducted in June 2018, with no limit of publication date.

Case controls, cohort studies and randomized clinical trials were searched in MEDLINE, LILACS, Scielo databases and Cochrane Database of Systematic Review. The descriptors and respective connectors used in PubMed were "elastography" [All Fields] AND "heart failure" [All Fields], with 44 articles retrieved; the descriptors used in BIREME were "elastography" AND "heart failure" AND (Collection:(“06-National/BR" OR “05-specialized") OR db: ("LILACS" OR "MEDLINE") AND (Collection: (“06-National/BR" OR “05-specialized") OR db: ("LILACS" OR "MEDLINE")) AND (MJ: ("imaging techniques by Elasticity" OR "heart failure") AND Type_of_study: ("case_control "OR "cohort") and limit: ("humans") and La: ("en"), with identification of five more articles; and the terms used in the search in Cochrane were "elastography " AND "heart failure", and no articles available were found. Then, a total of 49 articles were retrieved.

The selection of the articles was made in two stages. In the first stage, two independent authors read the abstracts and those that did not fit the inclusion criteria were excluded. In the second stage, the remaining studies were read in full and, similarly, those that did not meet the inclusion criteria according to the PRISM 10 model were excluded (Figure 1). At the end, seven articles were included in the review.

\section{Results}

This systematic review aimed to identify the scientific evidence on the use of elastography in HF. The results showed an important correlation between liver stiffness and markers of increased venous capillary pressure. ${ }^{7,10-13}$ In addition, liver elastography performed at hospital discharge was able to predict rehospitalization and mortality. ${ }^{13}$

In the seven selected articles, patients were evaluated in the hospital and there was a variation in the number of study participants. The most commonly used methods for the diagnosis and evaluation of HF were echocardiography in conjunction with measurements of B-type natriuretic peptide (BNP) or N-terminal pro-B type natriuretic peptide (NT-proBNP). However, no standardization of these methods was found in most of these articles. There was a low variation in the cutoff values of elastography and some authors reported a range for normal and abnormal values (Table 1). All studies showed a correlation between increased liver stiffness and elevation of BNP or NT-ProBNP levels in the admission. ${ }^{1,11,12}$

Colli et al. ${ }^{14}$ observed that most patients with acute HF had liver stiffness values and NT-proBNP levels that 


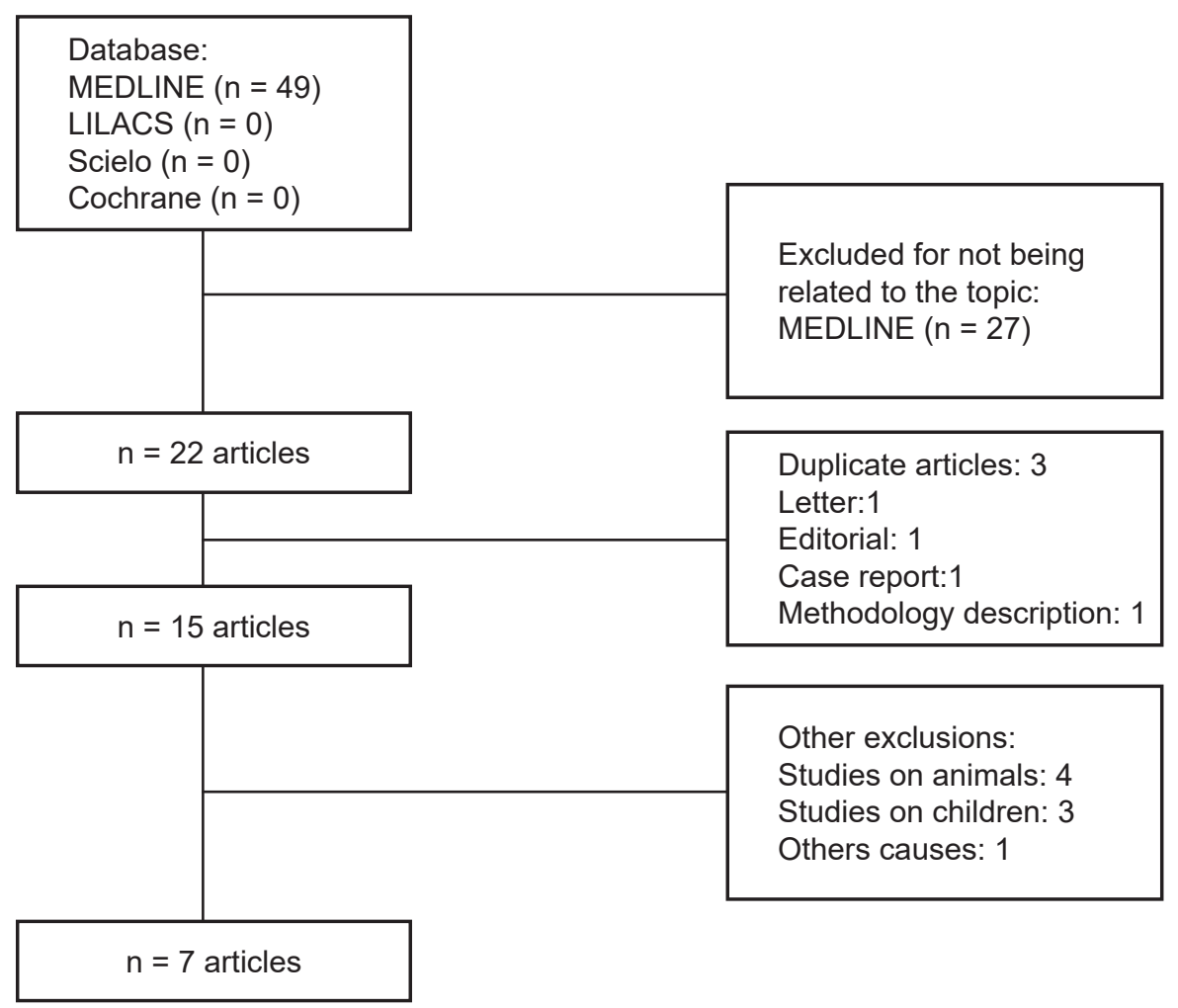

Figure 1 - Flowchart of study selection following the Preferred Reporting Items for Systematic Reviews and Meta-Analyses (PRISMA) statement.

tended to decrease with clinical improvement. Natriuretic peptides are released in response to volume overload and increased pressure in cardiac cavities and their levels reflect systolic and diastolic functions, as well as right ventricular function. ${ }^{14}$

Nishi et al. ${ }^{11}$ found that liver stiffness correlated with preoperative severity in patients with severe HF and reflected hepatic congestion and may be useful in predicting right atrial pressure measurement and post-operative complications in patients who underwent left ventricular assist device implantation. This was the first study to measure the variation of liver stiffness and its relationship with clinical outcome and laboratory data, including BNP levels. ${ }^{11}$ Lindvig et al. ${ }^{13}$ observed a high value of liver stiffness at admission associated with increased mortality, hepatic cirrhosis and congestive $\mathrm{HF}$, with a mortality rate of $20.8 \%$ in patients with transient elastography greater than $8.0 \mathrm{kPa}$. Taniguchi et al. ${ }^{12}$ suggested liver stiffness as a systemic volume index and predictor of HF severity, similarly to Alegre et al., ${ }^{7}$ who also reported an association of hepatic congestion with worsening of patient outcome.
An important finding of these reports was the fact that the volume withdrawal by diuretic therapy or hemodialysis did not alter the values of elastography at short time. ${ }^{7}$ Another study showed an improvement in elastographic values even though they did not reach standards of normality after cardiac decompensation. ${ }^{14}$

\section{Discussion}

Increased filling pressure of the right cavities can result in venous congestion, which is considered a determinant factor for systemic injury, cirrhosis and death. ${ }^{8,11}$ Elastography is a method that has been recently used to evaluate hepatic congestion. It is a painless, quick ( $<10$ minutes in the bedside), safe examination, and that has a good acceptance by patients, especially in case of repeated examinations. ${ }^{15}$

Despite increasing evidence of the benefits of this method in the management of patients with HF, elastography is still little explored. The cutoff values of BNP and NT-proBNP for the diagnosis of acute HF have 
Table 1 - Summary of the results of the studies included in this systematic review

\begin{tabular}{|c|c|c|c|c|c|c|}
\hline Authors & $\begin{array}{l}\text { Number } \\
\text { of patients }\end{array}$ & Male & $\begin{array}{c}\text { BNP } \\
(\mathrm{pg} / \mathrm{mL})\end{array}$ & $\begin{array}{c}\text { NT-proBNP } \\
(\mathrm{pg} / \mathrm{mL})\end{array}$ & p-value & Elastography \\
\hline $\begin{array}{l}\text { Saito et al. } \\
2018\end{array}$ & 105 & 73 & - & $\begin{array}{l}5.175 \text { (IQR. 2.586-11.1695) } \\
\text { in patients with < } 8.8 \mathrm{kPa} \text {; } \\
5.432 \text { (IQR. 2.338-11.527) in } \\
\text { patients with > 8.8 } \mathrm{kPa}\end{array}$ & $\begin{array}{c}0.052 \\
(<0.05)\end{array}$ & $\begin{array}{l}\text { Low }(<8.8 \mathrm{kPa})-52 \text { patients. } \\
\text { High }(>8.8 \mathrm{kPa})-53 \text { patients }\end{array}$ \\
\hline $\begin{array}{l}\text { Taniguchi } \\
\text { et al. } 2018\end{array}$ & 171 & 116 & $\begin{array}{c}199 \\
\text { (tertile } \\
91-356)\end{array}$ & - & $\begin{array}{c}0.019 \\
(<0.05)\end{array}$ & $\begin{array}{c}5.6 \mathrm{kPa} \text { (average). }>6.9 \mathrm{kPa} \text { in } \\
\text { patients with estimated right } \\
\text { atrial filling pressure }>7.1 \mathrm{mmHg}\end{array}$ \\
\hline $\begin{array}{l}\text { Nishi et al. } \\
2015\end{array}$ & 30 & 21 & $\begin{array}{l}844 \pm 806 \\
\text { (Standard } \\
\text { deviation) }\end{array}$ & - & - & $\begin{array}{c}13.3 \mathrm{kPa} \text {. preoperative }>7.0 \mathrm{kPa} \\
\text { with atrial-ventricle assistance } \\
(\mathrm{AVD}) ;>12.5 \mathrm{kPa} \text { correlated with } \\
\text { postoperative death }\end{array}$ \\
\hline $\begin{array}{l}\text { Alegre et } \\
\text { al. } 2013\end{array}$ & 26 & - & - & $\begin{array}{l}\text { 1,511 versus 3,535 (CHF } \\
\text { vs AHF at admission, } \\
\text { respectively); decrease } \\
\text { from 3,535 } \mathrm{pg} / \mathrm{ml} \text { to a } \\
\text { median of } 1,098 \mathrm{pg} / \mathrm{ml} \text { at } \\
\text { discharge (after clinical } \\
\text { compensation) }\end{array}$ & $\begin{array}{c}0.025 \\
(<0.05)\end{array}$ & $\begin{array}{c}6.5 \mathrm{vs} 14.4 \mathrm{kPa}(\mathrm{p}=0.009) \text { in } \\
\text { admission and } 8.2 \mathrm{kPa} \text { in hospital } \\
\text { discharge }(\mathrm{p}=0.008)\end{array}$ \\
\hline $\begin{array}{l}\text { Hopper et } \\
\text { al. } 2012\end{array}$ & 116 & 61 & - & $\begin{array}{c}4596+-4237 \\
\text { (Standard deviation) }\end{array}$ & - & $\begin{array}{l}\text { Healthy individuals } \mathrm{n}=55.4 .4 \\
\mathrm{kPa}(\text { percentile } 25-3.6 \text {. percentile } \\
\text { 75- 5.1); individuals with left } \\
\text { heart disfunction } 4.7(4.0 .8 .0) \mathrm{kPa} \\
\qquad(\mathrm{p}=0.04) \\
\text { Stable HF } 9.7(5.0 .10 .8) \mathrm{kPa} \\
(\mathrm{p}<0.001) \\
\text { Decompensated HF 11.2 } \\
\text { (6.7. 14.3) } \mathrm{kPa}(\mathrm{p}<0.001)\end{array}$ \\
\hline $\begin{array}{l}\text { Lindvig et } \\
\text { al. } 2012\end{array}$ & 289 & 289 & - & - & - & $\begin{array}{l}>8.0 \mathrm{kPa}(48 / 212) \text { cirrhosis and } \\
\text { hepatic congestion; independent } \\
\text { mortality predictor }\end{array}$ \\
\hline $\begin{array}{l}\text { Colli A; } \\
2010\end{array}$ & 27 & 12 & - & $\begin{array}{c}\text { 7,114 (IQR 2,939-13,437) } \\
\text { in admission and 4,127 } \\
\text { (IQR 947-5955) at hospital } \\
\text { discharge, with median } \\
\text { decrease of 3,128(IQR } \\
\text { 1,373-6,157) }\end{array}$ & $\begin{array}{l}<0.001 \\
(<0.05)\end{array}$ & $\begin{array}{c}\text { Admission }>7.65 \mathrm{kPa} \text { in } 14 \text { of } 24 \\
\text { patients and } 5(21 \%) \text { more than } \\
13.01 \mathrm{kPa} \text { and } 14>7.65 \mathrm{kPa} \text { at } \\
\text { hospital discharge }\end{array}$ \\
\hline
\end{tabular}

BNP: B-type natriuretic peptide; NT-proBNP): N-terminal pro-B type natriuretic peptide; IQR: interquartile range; CHF compensated chronic heart failure; AHF acute decompensated heart failure.

varied considerably among the studies and have not been reported in all studies of this review, bringing difficulty to data interpretation.

There is a lack of continous parameters in the evaluation of individuals studies selected for the systematic review. Besides that, the small number of samples, reduced quantity of articles with statistical relevant power and wich relate the method to the issue of HF brings a difficulty in standardizing the assessment of the method.

The studies did not compare elastography with liver biopsy, which is the gold standard for evaluation of derangement of liver architecture. However, while biopsy is an invasive method, and hence difficult to be reproduced, elastography is a non-invasive method that can be used in different liver diseases. It is worth 
mentioning, however, that liver elastography is an examiner-dependent method which requires adequate training. Furthermore, there is no standardization in the analysis of the results.

Patients with liver disease and cirrhosis have higher elastography values than patients with other chronic diseases and were then excluded from the studies to avoid confounding factors.

There was a divergence on whether liver stiffness improves with diuretic treatment compared with elastography in a short period of time, which shows the importance of a long-term follow-up, since this could have a positive impact on morbimortality. In addition, it is believed that elastography can be used as a response tool to clinical or supportive therapy, or as a prognostic tool in HF treatment.

\section{Conclusion}

Data on the use of elastography in the evaluation of patients with different stages of HF, such as stable, acute or chronic decompensated HF, and of patients undergoing left ventricular assist device implantation is still scarce and more data are needed. The method seems to increase the diagnostic power of the elevation in the filling pressures of the right cavities and, consequently, increased liver stiffness. The effects of heart disease on liver function may be silent, not detected by physical examination or laboratory tests, and in this context, elastography seems to be the ideal non-invasive method for assessing liver damage caused by cardiovascular disease. This analysis can help in the clinical management of these patients and be of prognostic value at hospital discharge.

\section{Author contributions}

Conception and design of the research: Avila DX. Acquisition of data: Avila DX, Lopes GQ, Matos PA. Analysis and interpretation of the data: Avila DX, Matos PA, Martins WA, Villacorta H, Mesquita CT, Machado D. Statistical analysis: Avila DX, Machado D. Writing of the manuscript: Avila DX, Matos PA. Critical revision of the manuscript for intellectual content: Avila DX, Martins WA, Villacorta H, Mesquita CT.

\section{Potential Conflict of Interest}

No potential conflict of interest relevant to this article was reported.

\section{Sources of Funding}

There were no external funding sources for this study.

\section{Study Association}

This article is part of the thesis of master submitted by Diane Xavier de Ávila, from Fluminense Federal University.

\section{Ethics approval and consent to participate}

This article does not contain any studies with human participants or animals performed by any of the authors.

\section{References}

1. Ceia F, Fonseca C, Mota T, Morais H, Matias F, de Sousa A, et al. Prevalence of chronic heart failure in Southwestern Europe: the EPICA study. Eur J Heart Fail. 2002;4(4):531-9.

2. Redfield MM, Jacobsen SJ, Burnett JC Jr, Mahoney DW, Bailey KR, Rodeheffer RJ. Burden of systolic and diastolic ventricular dysfunction in the community: appreciating the scope of the heart failure epidemic. JAMA. 2003;289(2):194-202.

3. Bleumink GS, Knetsch AM, Sturkenboom MC, Straus SM, Hofman A, Deckers JW, et al. Quantifying the heart failure epidemic: prevalence, incidence rate, lifetime risk and prognosis of heart failure The Rotterdam Study. 2004;25(18):1614-9.

4. Jorge AJL, Rosa MLG, Fernandes LCM, Freire MDC, Correia DMS, Rodrigues RC, et al. Heart failure prevalence study among patients enrolled in the family health program, Niterói. The DIGITALIS Study: design and method. Rev Bras Cardiol. 2011;24(5):320-5.

5. Albuquerque DC, Neto JD, Bacal F, Rohde LE, Bernardez-Pereira S, Berwanger O, et al. I Brazilian Registry of Heart Failure - clinical aspects, care quality and hospitalization outcomes. Arq Bras Cardiol. 2015;104(6):433-42.

6. Owan TE, Hodge DO, Herges RM, Jacobsen SJ, Roger VL, Redfield MM Trends in Prevalence and outcome of heart failure with preserved ejection fraction. N Eng J Med. 2006;355(3):251-9.

7. Alegre F, Herrero JI, Iñarrairaequi M, Gavira JJ, Pujol C, Montero A, et al. Increased liver stiffness values in patients with heart failure. Acta Gastroenterol Belq. 2013;76(2):246-50.

8. Hopper I, Kemp W, Porapakkham P, Sata Y, Condon E, Skiba M, et al. Impact of heart failure and changes to volume status on liver stiffness: non-invasive assessment using transient elastography. Eur J Heart Fail. 2012;14(6):621-7. 
9. Saito Y, Kato M, Nagashima K, Monno K, Aizawa Y, Okumura Y, et al. Prognostic relevance of liver stiffness assessed by transient elastography in patients with acute decompensated heart failure. Circ J. 2018;82(7):1822-9.

10. Moher D, Shamseer L, Clarke M, Ghersi D, Liberati A, Petticrew M, et al. Preferred reporting items for systematic review and meta-analysis protocols (PRISMA-P) 2015 statement. Syst Rev. 2015 Jan 1;4:1.

11. Nishi H, Toda K, Miyagawa S, Yoshikawa Y, Fukushima S, Kawamura $\mathrm{M}$, et al. Novel method of evaluating liver stiffness using transient elastography to evaluate perioperative status in severe heart failure. Circ J. 2015;79(2):391-7.

12. Taniguchi T, Ohtani T, Kioka H, Tsukamoto Y, Onishi T, Nakamoto K, et al. Liver stiffness reflecting right-sided filling pressure can predict adverse outcomes in patients with heart failure. JACC Cardiovasc Imaging. 2019;12(6):955-64.

13. Lindvig K, Mössner BK, Pedersen C, Lillevang ST, Christensen PB. Liver stiffness and 30-day mortality in a cohort of patients admitted to hospital. Eur J Clin Invest. 2012;42(2):146-52.

14. Colli A, Pozzoni P, Berzuini A, Gerosa A, Canovi C, Molteni EE, et al. Decompensated chronic heart failure: increased liver stiffness measured by means of transient elastography. Radiology. 2010;257(3):872-8.

15. Perazzo H, Veloso VG, Grinsztejn B, Hyde C, Castro R. Factors that could impact on liver fibrosis staging by transient elastography. Int J Hepatol. 2015;2015:624596. 